\title{
Evaluating the Impact of Holistic Remediation on Oil Spill Polluted Soils in Parts of Niger Delta, Nigeria.
}

NWANKWO, IFEYINWA LUCIANA ${ }^{1}$, IGWE, OGBONNAYA ${ }^{1}$ AND UCHE O. CHUKWURA ${ }^{1}$

${ }^{1}$ Department of Geology, faculty of Physical Sciences, University of Nigeria Nsukka, Enugu, Nigeria.

Corresponding author email:

ifeyinwanwankwo87@gmail.com

Oil spill remediated soils were studied to evaluate the impact of the general remediation carried out over years and to ascertain observable variation in environmental quality. Important physicochemical parameters of environmental concern in soil were determined in the laboratory by analyzing samples of soils collected from the remediated sites. The descriptive statistical evaluation of samples showed that the hydrogen ion concentration $(\mathrm{pH})$ values for the top and bottom soils were within the acidic range and some total petroleum hydrocarbon (TPH) values were higher than the department of petroleum resources (DPR) target limits of $50 \mathrm{mg} / \mathrm{kg}$. While heavy metals such as Chromium, Lead, Copper, Nickel and Zinc had low values except Cadmium having values above the DPR target limit of $0.8 \mathrm{mg} / \mathrm{kg}$. A one-way ANOVA and Turkey HSD post hoc test conducted on the topsoil sample groups showed significant difference (significant alpha level, $p<0.05$ ) between the applied remediation. Similar result was obtained for the bottom soil sample groups except for groups evaluated for Zinc concentration levels which showed that there was no significant difference between the applied remediation $(P>0.05)$. Generally, the remediation applied over the years had variable impacts in some physicochemical parameters and environmental quality. There was improvement in soil quality with respect to reduced $\mathrm{TPH}$, polyaromatic hydrocarbon (PAH), Benzene, Toluene, Ethylene and Xylene (BTEX) and concentrations of most heavy metals were reduced while some parameters such as the $\mathrm{pH}, \mathrm{Cd}$, Iron ( $\mathrm{Fe}$ ) were not impacted by the remediation. 